\title{
Effects of the Cervical Marginal Relocation Technique on the Marginal Adaptation of Lithium Disilicate CAD/CAM Ceramic Crowns on Premolars
}

\author{
Nasser M Alahmari ${ }^{1}$, Hafiz A Adawi $^{2}{ }^{\circ}$, Mohammed M Al Moaleem ${ }^{3} \odot$, Faris M Alqahtani ${ }^{4}$, Fahad T Alshahrani ${ }^{5}$, \\ Thiyezen A Aldhelai ${ }^{\circ}$
}

\begin{abstract}
Aim and objective: To evaluate the effect of cervical margin relocation (CMR) for crowns designed using CAD/CAM technology and fabricated from lithium disilicate (e.max, CAD) before and after aging; and to compare the fracture forces and failure type of the tested crowns.

Materials and methods: Mesio-occluso-distal(MOD) cavities $1 \mathrm{~mm}$ above the cementoenamel junction(CEJ) were prepared on $40 \mathrm{maxillary}$ first premolars. The teeth were divided into four groups. In group A, all cervical margins (CM) were located $1 \mathrm{~mm}$ above the CEJ. However, in both mesial and distal proximal boxes of groups $B, C$, and $D$, in addition to the MOD cavities, the CMs were extended 2 mm on both sides below the CEJ apically to simulate the CMR technique. In group B, the mesial and distal proximal boxes were filled with flowable composite, while for group C and group D, specimens were filled with composite resin fillings. To simulate the CMR technique, the cavities were filled with composite layers of $3 \mathrm{~mm}$ in two increments. Using the CAD/CAM system, 40 standard crowns were prepared on premolars, then cemented using a dual-curing adhesive cement. Assessments of the marginal integrity of interfaces of the proximal boxes of the cemented crowned teeth were recorded. Statistical differences between groups were analyzed using the ANOVA and Bonferroni's posthoc test.

Results: The first null hypothesis was accepted since no statistically significant differences were found in marginal integrity before and after aging $(p>0.05)$, while the second was partially rejected since different fractured force values were recorded and a significant difference was detected between group $\mathrm{D}$ and group $\mathrm{B}$. The third hypothesis was rejected because the catastrophic fracture rate was the highest among the four groups. Conclusion: The implementation of CMR before and after aging had a good effect on the marginal integrity of CM relocation. The CMR technique with resin luting cement of lithium disilicate crowns is effective and recommended for the restoration in deep proximal boxes of premolars or posterior teeth.

Clinical significance: CAD/CAM-generated e. max all-ceramic crowns with composite as the CMR enable the reconstruction of severely destroyed teeth irrespective of the position of the cavity margins.

Keywords: Deep margin relocation, Deep proximal caries, Fracture forces, Lithium disilicate ceramic, Marginal integrity.

The Journal of Contemporary Dental Practice (2021): 10.5005/jp-journals-10024-3138
\end{abstract}

\section{INTRODUCTION}

The proximal box elevation (PBE) procedures were initially proposed by Dietschi et al. through visual examination and assessment of deep restorations. ${ }^{1}$ The cervical or coronal margin relocation (CMR) was estimated more than 15 years ago, and in the past decade, it has become more widespread among general practitioners or specialist dentists. ${ }^{2,3}$ Other terms used for the same technique include margin elevation technique (MET) and deep marginal elevation. Those surgical procedures allowed positioning of composite fillings or glass ionomer restorations in the proximal box prior to the incorporation of ceramic restorations and might result in marginal integrities similar to margins of ceramic prostheses cemented in dentin or cementum. ${ }^{4-6}$ Those techniques are indicated when the gingival margin of the interproximal cavity cannot be isolated with rubber dam alone, an alternative approach to accomplish surgical crown lengthening. It consists of placing a base of direct resin composite using a suitable interproximal matrix. Subsequently, CMs can be recorded by impression and/or intraoral optical scanning. ${ }^{7-9}$

IPS e.max CAD is a lithium-disilicate system including a widerange of products for diverse usages and processing systems. ${ }^{10}$ This material is widely used since it offers maximum aesthetics and high fracture resistance. ${ }^{11}$ The e.max with 1.0 to $1.2 \mathrm{~mm}$ can be used in fabricating ceramic crowns for posterior
${ }^{1}$ Prosthetic Department, College of Dentistry, King Khalid University, Abha, Saudi Arabia

2,3 Department of Prosthetic Dental Science, College of Dentistry, Jazan University, Jazan, Saudi Arabia

${ }^{4,5}$ Dental Intern, College of Dentistry, King Khalid University, Abha, Saudi Arabia

${ }^{6}$ Department of Orthodontic and Pediatric Dentistry, College of Dentistry, Qassim University, Buraydah, Saudi Arabia; Department of Orthodontics and Pediatric Dentistry, Faculty of Dentistry, Ibb University, Ibb, Yemen

Corresponding Author: Mohammed MAI Moaleem, Department of Prosthetic Dental Science, College of Dentistry, Jazan University, Jazan, Saudi Arabia, e-mail: Drmoaleem2014@gmail.com

How to cite this article: Alahmari NM, Adawi HA, Al Moaleem MM, et al. Effects of the Cervical Marginal Relocation Technique on the Marginal Adaptation of Lithium Disilicate CAD/CAM Ceramic Crowns on Premolars. J Contemp Dent Pract 2021;22(8):900-906.

Source of support: Nil

Conflict of interest: None

teeth. ${ }^{12}$ Brandt et al. recorded a high survival rate for 1,058 crowns or fixed partial dentures constructed with the IPS e.max system

(0) The Author(s). 2021 Open Access This article is distributed under the terms of the Creative Commons Attribution 4.0 International License (https://creativecommons. org/licenses/by-nc/4.0/), which permits unrestricted use, distribution, and non-commercial reproduction in any medium, provided you give appropriate credit to the original author(s) and the source, provide a link to the Creative Commons license, and indicate if changes were made. The Creative Commons Public Domain Dedication waiver (http://creativecommons.org/publicdomain/zero/1.0/) applies to the data made available in this article, unless otherwise stated. 
over 5 years. The average cumulative survival rate was $94.22 \%$, with superior outcomes with the different systemsused.Therefore, these authors advised that rehabilitation of teeth in the aesthetic areas with this type of all-ceramic type is suitable:It is the system of choice to treat most of the clinical cases since it offers excellent periodontal health and color stability over a period of time, ${ }^{11}$ it is a conservative material, it is predictable and durable, and it shows excellent aesthetics, strength, marginal fit, and biocompatibility intheoral cavity. ${ }^{13,14}$

A clinical study by Bressera et al. evaluated the survival rate (by Kaplan-Meier estimates test) of 197 supragingivally largesized indirect CM restorations (composites or ceramics) with Deep marginal elevation (DME) of different dimensions in the posterior area. These authorsdetermined that both types of indirect restorations with CMR have a good survival rate. ${ }^{15}$ Juloski et al. summarized the published literature reviewing PBE, CMR, MET, and DME techniques prior to the adhesive cementation of the indirect restorations. They concluded that there is no strong scientific evidence that could either support or discourage the use of the CMR technique prior to the restoration of deep-seated subgingival deficiencies with indirect adhesive crowns. ${ }^{5}$

In vitro research addressing those techniques has been carried out using artificial models, ${ }^{16,17}$ or natural teeth, ${ }^{4,6,9,18}$ with either composite or ceramic restorations as indirect restorations, such as inlays, ${ }^{4,19,20}$ onlays, ${ }^{9,12,21,22}$ or crown restorations. ${ }^{23,24}$

There is a lack of studies with a full-crown design investigating and assessing the effectiveness of these techniques among premolars. Thus, the purpose of this in vitro study was to evaluate the effect of the CMR technique by the application of resin material increments in deep cervical cavities on the marginal adaptation of adhesive lithium disilicate CAD/CAM ceramic crowns. The null hypothesis was that no percentage or significant differences would be detected in margin quality of ceramic crowns cemented in enamel-dentine-cementum with or without proximal margin relocation, and that the values of the fracture forces and failure types would be the same in all groups.

\section{Materials and Methods}

\section{Study Design}

This in vitro laboratory study was carried out at the College of Dentistry, King Khaled University, Abha, Saudi Arabia. It measured both strength and marginal integrity of IPS e.max CAD-fabricated ceramic crowns. Independent variables consisted of (1) gingival margin position (enamel and cementum) and (2) margin relocation restorative material (Flowable composite, Composite, and IPS e.max $(A D)$. Dependent variables were structural and marginal integrity, evaluated by visualizing the continuity of the margin at different locations, fracture strength, and types of the IPS e.max CAD crown failures.

\section{Specimen Collection and Mounting}

A total of 40 intact, caries-free human maxillary first premolar teeth (extracted for orthodontic reasons) with completed root formation were collected from private clinics in Abha city, Saudi Arabia. During the gathering, the extracted teeth were stored in $0.1 \%$ thymol solution until preparation time, cleaned by nonfluoride prophylaxis paste, and dried. The roots of the extracted teeth were fixed in a box (the dimensions of those boxes were in accordance with the testing machine dimension) with sticky wax, then the auto-polymerizing resin was mixed and filled all around the box of extracted teeth, and the clinical crown exposed with $2 \mathrm{~mm}$ beyond cementoenamel junction (CEJ).

\section{Teeth Grouping and Cavities Preparations}

A total of 40 standardized non-beveled mesio-occluso-distal (MOD) class II cavities were prepared ( $1 \mathrm{~mm}$ above the CEJ) under normal conditions using diamond burs as described by Shillingburg et al. ${ }^{25}$ The specimens were divided into four groups (10specimens for each group). In group A, all cervical margins (CMs) were located $1 \mathrm{~mm}$ above CEJ (Figs 1A1). However, in both mesial and distal proximal boxes of the groups $B, C$, and D, in addition to the MOD cavities, a CM was extended $2 \mathrm{~mm}$ below the CEJ apically, adding to the $1 \mathrm{~mm}$ ( $3 \mathrm{~mm}$ depth) above the CEJ on both sides of the specimens (Figs 1B1, 1C1, 1D1).

\section{Cavities Fillings, Finishing, and Polishing}

The proximal boxes at mesial and distal sides extended $2 \mathrm{~mm}$, with $1 \mathrm{~mm}$ above of the CEJ of group B, were filled with flowable composite, while the proximal boxes of group $C$ and group $D$ specimens were filled with composite resin fillings. To simulate the CMR technique, the cavities were filled with composite layers of $3 \mathrm{~mm}$ in the form of two increments (each increment was $1.5 \mathrm{~mm}$ thick). All the MOD cavities were filled with a highly filled light-curing restorative Microhybrid Tetric composite material (Ivoclar vivadent, Germany), while the flowable composite Premise Flow (Kerr, United States) was used. Enamel, dentine etching, and bonding were carried out with three-step total-etch adhesive Syntac Primer, Syntac Adhesive, Heliobond (Ivoclar Vivadent, Germany), placement and curing of composite, finishing (fine diamond burs), and polishing (polishing disks under continuous water cooling and descending roughness) of proximal composite layers were carried out according to the manufacturer instructions. Cavities were finished under magnification using all-ceramic and composite finishing and polishing burs kits. Lenses assessed the polishing procedures with $5 \times$ magnification using a rechargeable headband mounted and medical magnifier head. Besides that, magnifying glasses with removable lenses can be adjusted to the two intensity-level lights for reading close work (Good Commodities Trading Co., Ltd, China). The Illumination light source was two pure white LED lights (Fig. 2). The specimens were finished and polished in dental college, King Khalid University, Abha, Saudi Arabia.

\section{Crown Preparation, Constructions, and Cementation}

All MOD cavities with their proximal box (both mesial and distal) were further prepared for e.max crowns (IPS e.max CAD system by Ivoclar Vivadent Company), according to a protocol mentioned by Spreafico et al., with some modifications, ${ }^{22}$ usinganocclusal thicknessof $1.5 \pm 0.25 \mathrm{~mm}, 1 \pm 0.25 \mathrm{~mm}$ in the axial wall, and a shoulder finish line with $1 \pm 0.25 \mathrm{~mm}$ width. ${ }^{12,16,24}$ The finish lines were located $1 \mathrm{~mm}$ above the CEJ (enamel) for groups A-C (A2, B2, C2), while for group $D$, the finish line was extended apically with $2 \mathrm{~mm}$ below CEJ (cementum) (D2). All preparations with their finish line were captured by CAD/CAM scanner and then mailed for core and crown constructions to standardize thickness of crowns using a IPS e.max CAD system by Ivoclar Vivadent systems and CAD Dental 3D Scanner (Foshion Medical System, Germany), with Design software: 3 Shapes Dental System Complete Restorative and 3 SHAPE Model E3 (SN/1TB1924039B). ${ }^{10}$ Next, the e.max crowns were milled at a private dental laboratory (Advanced Dental Laboratory, Abha, Saudi Arabia) using a CAM Milling machine, KULZER CARA MILL 3.5, with CAM Software: MILL CAM5 SMART (Kulzer Company, Germany), with 

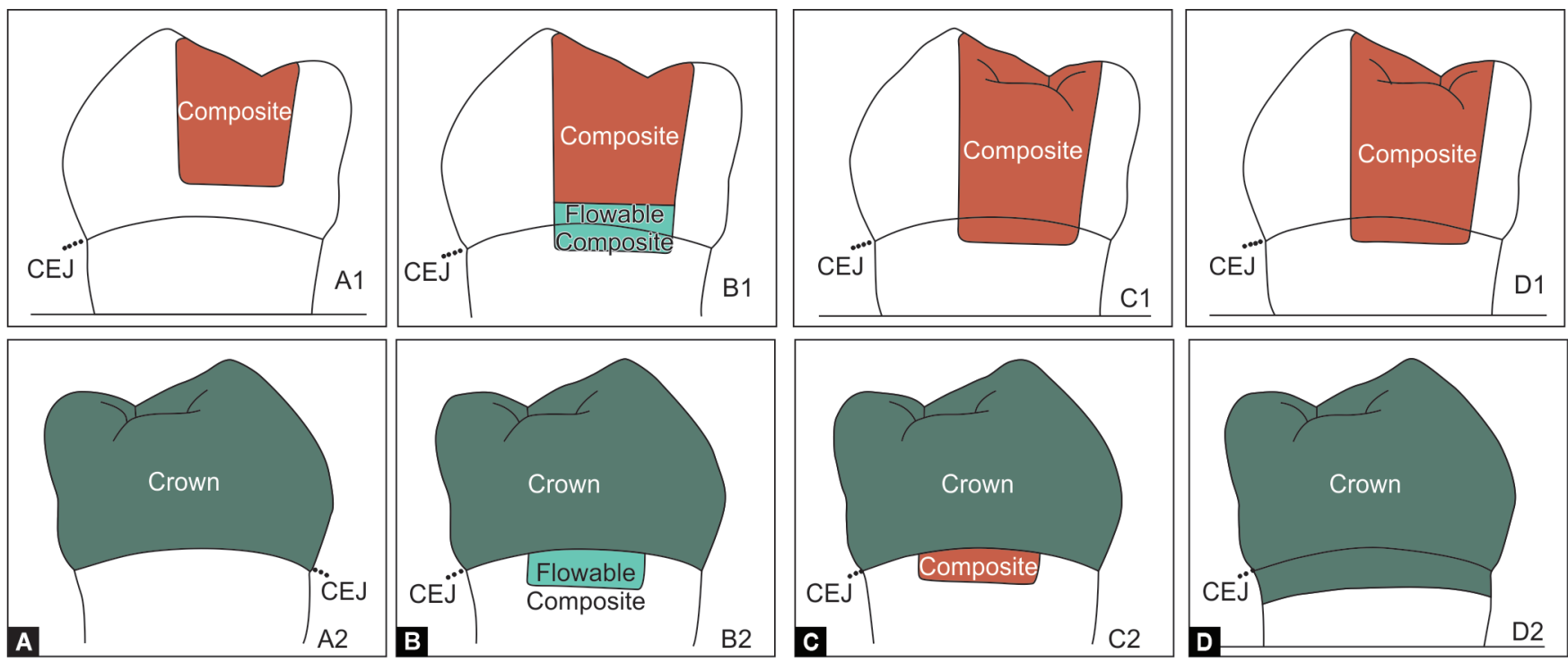

Figs $1 A$ to $D$ : (A1 and A2) MOD composite, same side with e.max-crowns (both without CMR); (B1 and B2) MOD composite proximal box with flowable composite and CMR, same side with e.max-crowns and CMR; (C1 and C2) MOD composite proximal box with resin composite and CMR, same side with e.max-crowns and CMR; (D1 and D2) MOD composite proximal box with resin composite with CMR, same side with e.max-crowns covering proximal box and CMR

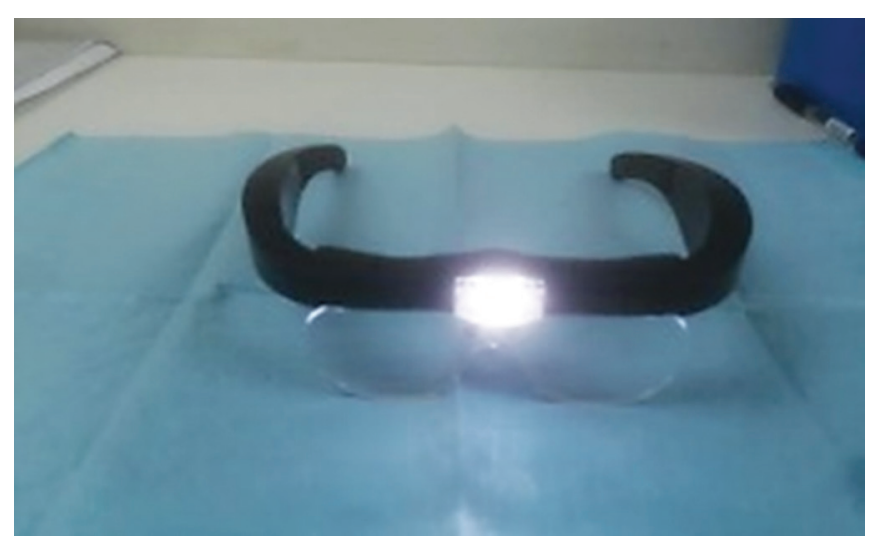

Fig. 2: Rechargeable headband magnifying glasses

Batch \# SN/699337/1. The cementation of crowns was carried out using self-adhesive resin (RelyX Ultimate (3M ESPE, Germany), coupling silane agent application, light curing, excess cement removal, finishing, and polishing of cement-crown junction, which were in accordance with manufacturer's instructions.

\section{Aging and Marginal Integrity Assessments}

The measurements of the mesial and distal sides were recorded after 2 weeks of aging (the samples were put inside an incubator at $37^{\circ} \mathrm{C}$ ). Those values were recorded as the marginal quality for cemented e.max crowns on the premolar teeth with or without the CMR technique (Figs 1A1, 1B2, 1C2, 1D2). Marginal integrity or quality was evaluated for each specimen at tooth-cement-crown interfaces mesially and distally either with CMR or without CMR technique. Each margin was categorized into "continuous margin," "gap/irregularity, " or "not assessable/artifact" (Table 1) as stated by previous studies. ${ }^{4,6,26,27}$ The marginal quality of specimens was assessed from mesial and distal sides separately and recorded as percentages. It was confirmed with a Hirox $\mathrm{KH}-1300$ digital microscope (Hirox, Hackensack, New Jersey, United States) under magnification $\times 35$ at College of Science, King Khalid University, Abha, Saudi Arabia.

\section{Measurement of Fractured Forces}

The maximum compressive fracture forces of the specimens were measured with a computer-controlled universal testing machine (Zwick Z010/TN2A, Ulm, Germany) at the across-head speed of $0.5 \mathrm{~mm} /$ minutes using a rod with $4 \mathrm{~mm}$ diameter. A $3 \mathrm{~mm}$ radius stainless steel hemispherical tip was applied to the center of each crown. A $0.6 \mathrm{~mm}$ thermoplastic resin film was positioned between the loading tip and occlusal e.max crown surfaces to distribute fracture forces and certify a broad uniform contact. The fracture forces were loaded along the longitudinal axis on the midline fissure of each specimen at the center of the crown until fracture, and the maximum breaking load of each sample was recorded automatically in Newton (N) by a computer connected to the loading machine. ${ }^{12,16,23,24}$ The fracture load for specimens was tested in the biomaterial laboratory in King Saud University, College of Dentistry, Riyadh, Saudi Arabia.

Table 1: Classification of marginal integrity of cemented e.max crowns with teeth ${ }^{4,6,9,26,27}$

\begin{tabular}{|c|c|}
\hline Criteria & Description \\
\hline Continuous margin & $\begin{array}{l}\text { No gap, no interruption of continuity. } \\
\text { Completely closed margin with intact resin } \\
\text { cement-crown without gaps or voids. }\end{array}$ \\
\hline $\begin{array}{l}\text { Presence of gap/ } \\
\text { irregular margins/ } \\
\text { imperfect }\end{array}$ & $\begin{array}{l}\text { Gap due to adhesive or cohesive failure; } \\
\text { restoration or enamel fractures related to } \\
\text { restoration margins }\end{array}$ \\
\hline Not assessable & Presence of artifact \\
\hline
\end{tabular}




\section{Failure Types Recording}

Fracture types or modes were categorized as chipping of ceramic from the e.max crown, visible crack lines on the crown only, catastrophic fracture, or combined fracture types as described by previous literature with some modifications. ${ }^{6,17,24,27}$ Fracture of the e.max crowns embedded in the acrylic base was classified according to the criteria presented in Table 2. The failure modes of specimens were checked visually and then confirmed with rechargeable headband, mounted, medical magnifier glasses with removable lenses (two LED lights) for close reading work ( $\times 4.5$, Good Commodities Trading Co., Ltd, China).

\section{Data Analysis}

The recorded data were recorded and analyzed using SPSS (Statistical Package for Social Science). Descriptive statistics are presented as mean and standard deviation (SD). Percentage of continuous margins (\% of total proximal margin length) were compared between mesial side and distal side after aging using ANOVA and Duncan's posthoc test. The failure types and percentages of each group were calculated.

\section{Results}

A 40 MOD cavities were prepared on human maxillary first premolars, then divided into four groups (10 for each group), and restored as previously mentioned. In Table 3 , the marginal integrity for each crown was measured before and after aging to determine the success rate in each group. The highest marginal integrity before aging was found in group $D$ (MOD cavities, then e.max crowns with CMs located $2 \mathrm{~mm}$ below the CEJ) (100\%). Groups A and C (Group A has a MOD cavity, then e.max crown with CMs located $1 \mathrm{~mm}$ above CEJ, while the with CMs located $1 \mathrm{~mm}$ below CEJ, leaving $2 \mathrm{~mm}$ of composite resin apically in group $\mathrm{C}$ ) had the same percentage

Table 2: Classification of fracture mode or types $6,17,24,27$

\begin{tabular}{|c|c|}
\hline Criteria (Fracture mode) & Description (definition) \\
\hline Chipping of crowns & $\begin{array}{l}\text { Only part of the veneering material was } \\
\text { chipped }\end{array}$ \\
\hline Presence of crack lines & $\begin{array}{l}\text { Presence of visible lines in different direc- } \\
\text { tion at the occlusal surfaces of the crowns }\end{array}$ \\
\hline Catastrophic fracture & Fracture of specimen surface at acrylic resin \\
\hline $\begin{array}{l}\text { Coronal tooth and } \\
\text { extended into root } \\
\text { embedded in resin }\end{array}$ & $\begin{array}{l}\text { Combined fracture involved crowns, tooth, } \\
\text { and root inresin }\end{array}$ \\
\hline
\end{tabular}

of marginal integrity before aging (80\%). Group B (MOD cavities with e.max crown with CMs located $1 \mathrm{~mm}$ above CEJ, leaving $2 \mathrm{~mm}$ flowable composite apically) has the least percentage of the marginal integrity before aging (60\%), and this value remains constant after aging. Besides that, there was no change in the percentage in group $A$, while it was decreased in groups $C$ and $D$ (70 and $80 \%$, respectively).

The comparisons between mean fracture forces between groups are shown in Table 4 and Figure 3. The highest significant compressive fracture force was in group D (2203 N), while the lowest significant compressive fracture force was found in group $B$ $(1671 \mathrm{~N})$, with a $p$-value $(\leq 0.01)$. There was no significant difference between the fracture forces when comparing groups A and C (1981 and $1866 \mathrm{~N}$, respectively), but there was a significant differencewhen comparing groups B and D. There was no significant difference regarding the type of failure among tested groups (Table 5). The catastrophic fracture rate was high (60-80\%) in all groups, followed by cracking in line forms (10-30\%).

\section{Discussion}

This study investigated and assessed the effect of composite resin material application in deeply cervical cavities on the marginal adaptation of adhesively luted lithium disilicate CAD/CAM ceramic crowns on the CMR technique on the natural teeth. The study was focused on the marginal integrity and fracture behavior of the luted crowns. The IPS e.max glass-ceramics shared the aesthetic, mechanical, and biocompatibility advantages for making dental crowns; the adding of aporcelain layer for the aesthetic layer was not essential. ${ }^{10-13}$ Also, the removal of additional tooth structure could be minimized, especially in patients of younger ages. Additionally, the application of a single-layer crown simplifies the production and facilitates the aim of conservative dentistry. ${ }^{12}$ Overall, the gained marginal integrity for MOD proximal cavities in the mesial or distal side of e.max cemented crowns with or without CMR was high (60-100\%) and considered a good technique. This is consistent with the literature. ${ }^{3,6,9,12}$ The recorded fracture forces strength values in $(N)$ in the present study ranged between 1638 and $2253 \mathrm{~N}$; these values were similar to the values obtained by Güngör and Nemli. ${ }^{24} \mathrm{Higher}$ fracture forces values were reported by Yu et al. and Chen et al., ${ }^{12,17}$ and similar values are listed by Grubbs et al., and Sieper et al. ${ }^{6,16}$

For patients with deep caries extended subgingivally, the restorative choices are surgical margin elevation, crown lengthening, or orthodontics, which can result in the removal of more tooth structure to adapt restorative materials. Also, surgery and orthodontics are costly and lengthy. ${ }^{6}$ In addition, in some cases,

Table 3: Percentage of the marginal integrity among the four tested groups before and after aging

\begin{tabular}{|c|c|c|c|c|c|c|c|}
\hline Types of restoration & Location & Aging & $\begin{array}{c}\text { Specimens } \\
\text { number }\end{array}$ & $\begin{array}{l}\text { Continuous } \\
\text { margin }\end{array}$ & $\begin{array}{l}\text { Defective } \\
\text { margin }\end{array}$ & $\begin{array}{l}\text { Non-judgeable } \\
\text { margin }\end{array}$ & $\begin{array}{l}\text { Percent of Marginal } \\
\text { integrity (success rate) }\end{array}$ \\
\hline \multirow{2}{*}{$\begin{array}{l}\text { MOD cavity, then e.max crown with CMs } \\
\text { located } 1 \mathrm{~mm} \text { above CEJ (A). }\end{array}$} & \multirow[t]{2}{*}{ Enamel } & Before & 10 & 8 & 1 & 1 & 80 \\
\hline & & After & 10 & 8 & 2 & 0 & 80 \\
\hline \multirow{2}{*}{$\begin{array}{l}\text { MOD cavity, then e.max crown with CMs } \\
\text { located } 1 \mathrm{~mm} \text { above CEJ, leaving } 2 \mathrm{~mm} \\
\text { flowable composite apically (B). }\end{array}$} & \multirow[t]{2}{*}{ Enamel } & Before & 10 & 6 & 3 & 1 & 60 \\
\hline & & After & 10 & 6 & 3 & 1 & 60 \\
\hline \multirow{2}{*}{$\begin{array}{l}\text { MOD cavity, then e.max crown with CMs } \\
\text { located } 1 \mathrm{~mm} \text { below CEJ, leaving } 2 \mathrm{~mm} \text { of } \\
\text { composite resin apically }(\mathrm{C}) \text {. }\end{array}$} & \multirow[t]{2}{*}{ Enamel } & Before & 10 & 8 & 2 & 0 & 80 \\
\hline & & After & 10 & 7 & 2 & 1 & 70 \\
\hline \multirow{2}{*}{$\begin{array}{l}\text { MOD cavity, then e.max crowns with CMs } \\
\text { located } 2 \mathrm{~mm} \text { below CEJ (D). }\end{array}$} & \multirow{2}{*}{$\begin{array}{l}\text { Cemen- } \\
\text { tum }\end{array}$} & Before & 10 & 10 & 0 & 0 & 100 \\
\hline & & After & 10 & 8 & 1 & 1 & 80 \\
\hline
\end{tabular}


Table 4: Multiple comparisons between mean compressive fracture forcesamong tested groups

\begin{tabular}{lccc}
\hline Type of restoration (group) & Mean \pm SD & Minimum & Maximum \\
\hline $\begin{array}{l}\text { MOD cavity, then e.max } \\
\text { crown with CMs located }\end{array}$ & & & \\
1 mm above CEJ (A). & $1981 \pm 223^{\mathrm{A}}$ & 1,690 & 2,342 \\
$\begin{array}{l}\text { MOD cavity, then e.max } \\
\text { crown with CMs located }\end{array}$ & & & \\
1 mm above CEJ, leaving & & \\
2 mm flowable composite & $1671 \pm 223^{\mathrm{B}}$ & 1,340 & 2,142 \\
apically (B). & & & \\
MOD cavity, then e.max \\
crown with CMs located
\end{tabular}

Means with different superscript capital letter are statistically significant at $p \leq 0.01$

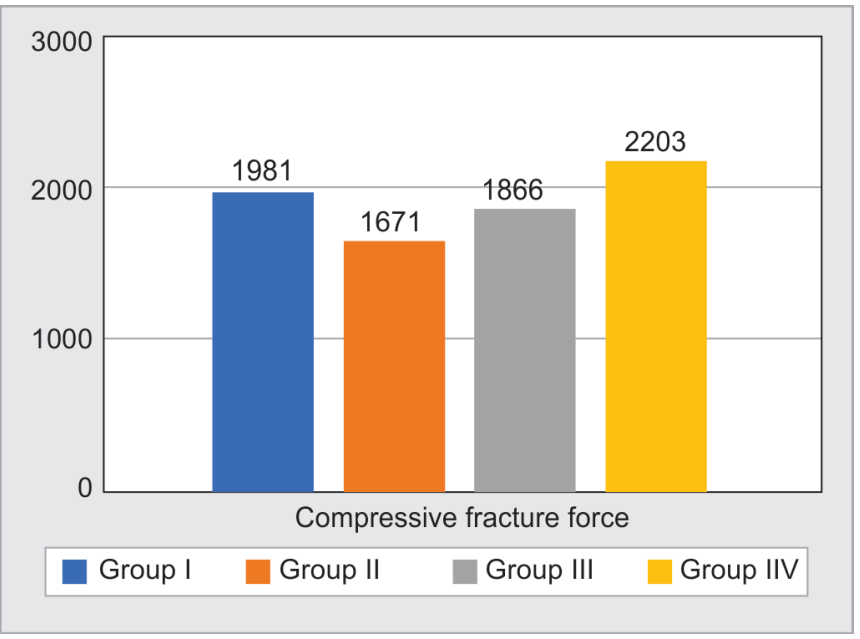

Fig. 3: Mean fractured force among groups $4,9,18,20,28$

the surgery choices might not be indicated, depending on their oral factors. So the CMR technique is indicated to restore these cases indirectly since it is considered a hopeful substitute. This technique canpreserve and minimize subject time, cost, and surrounding biological tissues. ${ }^{6,8,21}$ Marginal integrity is key to the success of restorations, resulting in long durability and a high survival rate of the prostheses. Continuous margins were registered as the highest percentage recorded in this study (60-100\%); the similarity of this percentage of continuous margins was found in laboratory studies conducted by Yu et al. and Spreafico et al., using e.max crowns with composite resin as the material of CMR. ${ }^{12,22}$ Other studies have used composite, flowable, composite, or glass ionomer as CMR material with ceramic inlays, ${ }^{4,9,19,20}$ or as ceramic onlays with composite resin. ${ }^{18}$ All the results of previous studies were in the range of the results counted by the current study in relation to different types of marginal integrity. So the first null hypothesis was accepted since no significant differences were detected in relation to marginal integrities.

A group of in vitro studies used different materials in CMR technique:ceramic Onlays (Ilgenstein et al. ${ }^{18}$ and ceramic inlays (Zaruba et al. ${ }^{4}$; Zaruba et al. ${ }^{9}$; Frankenberger et al., ${ }^{19}$ Muller et al., ${ }^{20}$ Marchesi et al., ${ }^{28}$ ). These authors identified no difference between samples with or without CMR regarding marginal integrity and fracture behaviors and could not be affected by the location of the CMR (enamel, dentine, or cementum). Frankenberger et al. ${ }^{19}$ and Muller et al. ${ }^{20}$ have suggested that CMR with adhesive resin cement exhibits significantly more gap in dentine compared to composite or flowable composite resin. Even though the above-citedstudies were either inlays or onlays, they agree with the current study outcome by using the CMR technique and e.max crowns.

Clinical studies were done for qualitative evaluation of the durability and the survival rate of teeth restored by the CMR technique. Those studies had recommended that the use of such techniques (PBE, DME, CMR, and MET) for relocating the cervical outline of a large-sized cavity in the posterior area., $814,15,21,29$ One hundred and ninety-seven restorations were evaluated using the modified United States Public Health Service (USPHS) criteria; the authors stated that an indirect restoration with CMR had recorded an accumulative survival rate of $95.9 \%$ up to 12 years. ${ }^{15}$ Ferrari et al. evaluated the procedure of an immediate CMR by placing a layer of a flowable composite resin after the application of the rubber dam and adapting metal matrix with a wedge to the emergence profile of the tooth by intraoral X-rays at the 12-month recall. These authors concluded that a higher incidence of bleeding on probing was expected around CMR margins and in coincidence with margins. CMR margins are a sensitive technique, especially when the deep subgingival margin is selected and restorative

Table 5: Descriptive statistics of the types of failure among four tested groups

\begin{tabular}{|c|c|c|c|c|c|c|c|}
\hline \multirow[b]{2}{*}{ Type of restoration (group) } & \multicolumn{5}{|c|}{ Type of failure } & \multirow[b]{2}{*}{ Total N (\%) } & \multirow[b]{2}{*}{$p$ value } \\
\hline & $\begin{array}{l}\text { Chipping N } \\
\text { (\%) }\end{array}$ & $\begin{array}{l}\text { Cracking in lines } \\
\text { forms } N(\%)\end{array}$ & $\begin{array}{l}\text { Catastrophic } \\
\text { fracture } N(\%)\end{array}$ & $\begin{array}{l}\text { Fracture of } \\
\text { the tooth }\end{array}$ & $\begin{array}{l}\text { Combined } \\
\text { fracture }\end{array}$ & & \\
\hline $\begin{array}{l}\text { MOD cavity, then e.max crown with CMs } \\
\text { located } 1 \mathrm{~mm} \text { above CEJ (A). }\end{array}$ & $1(10)$ & $3(30)$ & $6(60)$ & $0(00)$ & $0(00)$ & 10 & \\
\hline $\begin{array}{l}\text { MOD cavity, then e.max crown with CMs } \\
\text { located } 1 \mathrm{~mm} \text { above CEJ, leaving } 2 \mathrm{~mm} \\
\text { flowable composite apically (B). }\end{array}$ & $2(20)$ & $2(20)$ & $6(60)$ & $0(00)$ & $0(00)$ & 10 & \\
\hline $\begin{array}{l}\text { MOD cavity, then e.max crown with CMs } \\
\text { located } 1 \mathrm{~mm} \text { below CEJ, leaving } 2 \mathrm{~mm} \text { of } \\
\text { composite resin apically (C) }\end{array}$ & $1(10)$ & $2(20)$ & $7(70)$ & $0(00)$ & $0(00)$ & 10 & 0.699 \\
\hline $\begin{array}{l}\text { MOD cavity, then e.max crowns with CMs } \\
\text { located } 2 \mathrm{~mm} \text { below CEJ (D). }\end{array}$ & $0(00)$ & $0(00)$ & $8(80)$ & $1(10)$ & $1(10)$ & 10 & \\
\hline Total N (\%) & $4(10)$ & $7(17.5)$ & $27(67.5)$ & $1(2.5)$ & $1(2.5)$ & $100 \%$ & \\
\hline
\end{tabular}


bonding procedures are performed below the cementum or enamel margins. ${ }^{8}$ Roggendorf et al., ${ }^{21}$ after 7 years, found $87 \%$ as asuccess on the survival rate of adhesively cemented all-ceramic CEREC CAD/CAM restorations and said that they are appropriate for the restoration of extended coronal cavities, while Kielbassa et al. ${ }^{14}$ reported that the CMR technique is effective only in selected cases. Zaruba et al. (in vitro studies) concluded that the PBE before the insertion of ceramic inlay results in marginal integrities not different from margins of ceramic inlays placed in dentin. ${ }^{4,9}$ All of these cited studies coincided with our finding because there were no significant differences in marginal integrity located in either enamel, dentine, or cementum.

Second hypothesis: The variance in the loaded fracture forces in Newton and fracture type between groups can be related directly inside the study. The highest mean of the fracture forces and SD were for group D 2,202 (147), while the least values were for group B 1,670 (237). Lesser fracture forces values were recorded by a group of laboratory studies used e.max CAD crowns as Ye et al., 1,527 (191) for $1.2 \mathrm{~mm}$ crown thickness (polymethyl methacrylate) and 1,827 (337) for $1.5 \mathrm{~mm}$ thickness, Chen et al., 1,377 N, with milled abutments, Jassim and Majeed $1085.4 \mathrm{~N}$ with maxillary first premolars. ${ }^{12,17,23}$ Similar fracture forces values were documented by Güngör and Nemli for cemented lithium disilicate crown on natural molarteeth. ${ }^{24} \mathrm{~A}$ higher fracture force value was recorded by Sieiper et al., who registered 3,365 (262) before aging and chewing stimulation periods, but 2,648 (311) after the chewing stimulation period, the values were considered as in margin to the current study values. ${ }^{16}$ Those differences in the values of the forces can be related to the type and the surface areas of the abutment (they used mandibular molar typodont, but we used maxillary premolar natural teeth), also the resin cement type (their crowns were cemented with Multilink Automix, but our crowns were cemented with RelyX Unicem Aplicap). For groups $A$ and $C$, the values of fracture forces and SD were near to each other's 1,981 (223) and 1,866 (176), respectively. Similar findings were noticed by Kielbassa and Phillipp, who reported that PBE represents a promising treatment regimen in relation to the marginal continuity, instantaneously encircling the benefits of direct dentin sealing and facilitating direct placement of flowable composite, then CAD/CAM indirect adhesive restorations (inlays, onlays, full crowns) of cavities with margins positioned below the gingival tissues, assuring the dental practitioner's awareness pre effective placement procedures. ${ }^{14}$ The fracture forces values of the present study coincided with results carried out by Chen et al., for full ceramic e.max crowns, ${ }^{17}$ Ilgenstein et al. with ceramic onlays, ${ }^{18}$ Frankenberger et al., and Muller et al., for ceramic inlays. ${ }^{19,20}$ In this parameter, the null hypothesis was accepted since no significant differences in values of fracture strength in $\mathrm{N}$ were detected between the different groups.

The null hypothesis was that no significant percentage differences were detected in margin quality of ceramic crowns cemented in enamel/cementum with or without proximal margin relocation. Also, the values of the fracture forces and failure types will be the same in all groups. There was a high statistically significant difference among the four groups. Therefore, the second null hypothesis, which stated that no statistically significant difference existed in the mean values of the fracture strength between the four groups, was accepted. The present study does agree with Chen et al. because they compared e.max with other restorative materials with different crown thickness and they used typodont; this might play a major role in the bonding mechanism between e.max crowns and composite crowns from one side and type of the abutment teeth on the other side. Also, there was no agreement with Yu et al., who used different thicknesses of lithium disilicate materials $(1,0,1.2 \mathrm{~mm}) .{ }^{12,17}$ However, our findings were in agreement with Jassim and Majeed, who compared crowns fabricated from lithium disilicate (IPS e.max CAD) (Ivoclar Vivadent, Liechtenstein) with other systems, and Yu et al., who used the same thickness $(1.5 \mathrm{~mm})$ of lithium disilicate materials. $^{12,23}$

All specimens were compressively loaded until they reach failure with a universal testing instrument and after the 15 days of aging. The four groups showed different types of fracture failures, with a single complete tooth fracture among the combined fracture in group D. On the other hand, the catastrophic fracture type was the highest among the four groups and represented as $60 \%$ for group A and B and $70-80 \%$ for group C and D, respectively. Therefore, the IPS e.max crowns cemented on natural premolar maxillary teeth demonstrated different types of ceramic-cementteeth failures. Based on that, fracture types of lithium disilicate CAD crowns affected by the elastic modulus of the substrate of the restorative materials were accepted as a third null hypothesis. Similar results were published by Grubbs et al. and Sieper et al. in relation to catastrophic failure but with lesser values were recorded by Chen et al. (30\%). This might be due to the different surface areas of his samples (molar teeth) and different cement used in their study. ${ }^{6,8}$ Regarding crack and chipping failure types, it was near to marginal values, which were recorded by Chen et al., Yu et al., and Vrotili et al. withinlay ceramic. ${ }^{12,17}$

RelyX Unicem Aplicap resin cement was used because the clinical survival rate has been documented by Federline et al. (who monitored the clinical durability of cemented Vita Mark II partial ceramic crowns), Bressera et al., and Roggendorf et al. These authors have concluded that the RelyX Unicem (selfadhesive resin cement) could be used in conjunction with selective enamel etching, and its survival rate was good after 3 years of follow-up. $15,18,21$

One limitation of the current study is the application of thermomechanical cycling for the specimens, which were not carried out. In addition, thermocycling was not applied to the specimens to simulate the oral cavity environment.

\section{Conclusion}

CMR is a suitable clinical technique for deep marginal cases. The highest marginal integrity (100\%) before aging and compressive fractured force values were recorded in MOD cavities for e.max crowns with CMs located $2 \mathrm{~mm}$ below CEJ, while the lowest (60\%) group was with MOD cavities with e. max crowns with CMs located $1 \mathrm{~mm}$ above CEJ, leaving $2 \mathrm{~mm}$ flowable composite apically. These values remainedthe same after aging. In addition, the lowest fracture force was found in MOD cavities with e.max crown with CMs located $1 \mathrm{~mm}$ above CEJ, with $2 \mathrm{~mm}$ flowable composite apically. Catastrophic fracture was the highest percentage followed by cracking inline forms, without any significance between the all groups. 


\section{ORCID}

Nasser M Al Ahmari $\odot$ https://orcid.org/0000-0002-6660-5200 Hafiz A Adawi $\odot$ https://orcid.org/0000-0003-4513-7230?lang=en Mohammed MAlMoaleem $\odot$ https://orcid.org/0000-0002-9623-261X Thiyezen A Aldhelai i https://orcid.org/0000-0003-1493-9492

\section{References}

1. Dietschi D, Spreafico R. Current clinical concepts for adhesive cementation of tooth-colored posterior restorations. Pract Periodontics Aesthet Dent 1998;10(1):47-54; quiz 6.

2. Köken S, Juloski J, Ferrari M. Influence of cervical margin relocation and adhesive system on microleakage of indirect composite restorations. J Osseointegration2019;11(1):21-28.DOI: 10.23805/ JO.2019.11.01.04.

3. Juloski J, KÖken S, Ferrari M. No correlation between two methodological approaches applied to evaluate cervical margin relocation. Dent Mater J 2020;39(4):624-632. DOI: 10.4012/dmj. 2018-410.

4. Zaruba M, Göhring TN, Wegehaupt FJ, et al. Influence of a proximal margin elevation technique on marginal adaptation of ceramic inlays. Acta Odontol Scand 2013;71(2):317-324.DOI: 10.3109/00016357.2012.680905.

5. Juloski J, Köken S, Ferrari M. Cervical margin relocation in indirect adhesive restorations: a literature review. J Prosthodont Res2018;62(3):273-280.DOI: 10.1016/j.jpor.2017.09.005.

6. Grubbs TD, Vargas M, Kolker J, et al. Efficacy of direct restorative materials in proximal box elevation on the margin quality and fracture resistance of molars restored with CAD/CAM onlays. Oper Dent 2020;45(1):52-61. DOI: 10.2341/18-098-L.

7. Magne $P$, Harrington $S$, Spreafico RC. Deep margin elevation: a paradigm shift. Am J Esthet Dent 2012;2(2):86-96.

8. Ferrari M, Koken S, Grandini S, et al. Influence of cervical margin relocation (CMR) on periodontal health: 12-month results of a controlled trial. J Dent2018;69:70-76. DOI: 10.1016/j.jdent.2017.10.008.

9. Zaruba M, Kasper R, Kazama R, et al. Marginal adaptation of ceramic and composite inlays in minimally invasive mod cavities. Clin Oral Investig2014;18(2):579-587. DOI: 10.1007/s00784-013-0988-1.

10. IPS e.max-All ceramic, all you need—clinical guide. In: Vivadent Al, editor. Liechtenstein; 2020.

11. Brandt S, Winter A, Lauer HC, et al. IPS e.max for all-ceramic restorations: clinical survival and success rates of full-coverage crowns and fixed partial dentures. Materials (Basel, Switzerland) 2019;12(3):462.DOI: 10.3390/ma12030462.

12. Yu T, Wang F, Liu Y, et al. Fracture behaviors of monolithic lithium disilicate ceramic crowns with different thicknesses. RSC Adv2017;7(41):25542-25548. DOI:10.1039/C6RA28847B.

13. Nazeer MR, Ghafoor R, Zafar K, et al. Full mouth functional and aesthetic rehabilitation of a patient affected with hypoplastic type of amelogenesis imperfecta. J Clin Exp Dent 2020;12(3):e310-e316. DOI:10.4317/jced.56217.

14. Kielbassa AM, Philipp F. Restoring proximal cavities of molars using the proximal box elevation technique: systematic review and report of a case. Quintessence Int 2015;46(9):751-764. DOI: 10.3290/j.qi.a34459.
15. Bresser RA, Gerdolle D, van den Heijkant IA, et al. Up to 12 years clinical evaluation of 197 partial indirect restorations with deep margin elevation in the posterior region. J Dent 2019;91:103227. DOI: 10.1016/j.jdent.2019.103227.

16. Sieper K, Wille S, Kern M. Fracture strength of lithium disilicate crowns compared to polymer-infiltrated ceramic-network and zirconia reinforced lithium silicate crowns. J Mech Behav BiomedMater 2017;74:342-348.DOI: 10.1016/j.jmbbm.2017.06.025.

17. Chen SE, Park AC, Wang J, et al. Fracture resistance of various thickness e.max CAD lithium disilicate crowns cemented on different supporting substrates: an in vitro study. J Prothodont 2019;28(9):9971004. DOI: 10.1111/jopr.13108.

18. Ilgenstein I, Zitzmann NU, Bühler J, et al. Influence of proximal box elevation on the marginal quality and fracture behavior of root-filled molars restored with CAD/CAM ceramic or composite onlays. Clin Oral Investig 2015;19(5):1021-1028. DOI: 10.1007/s00784-014-1325-z.

19. Frankenberger $\mathrm{R}$, Hehn J, Hajtó J, et al. Effect of proximal box elevation with resin composite on marginal quality of ceramic inlays in vitro. Clin Oral Investig 2013;17(1):177-183. DOI: 10.1007/ s00784-012-0677-5.

20. Müller V, Friedl K-H, Friedl K, et al. Influence of proximal box elevation technique on marginal integrity of adhesively luted Cerec inlays. Clin Oral Investig 2017;21(2):607-612. DOI: 10.1007/s00784-016-1927-8.

21. Roggendorf MJ, Kunzi B, Ebert J, et al. Seven- year clinical performance of CEREC-2 all-ceramic CAD/CAM restorations placed within deeply destroyed teeth. Clin Oral Investig 2012;16(5):1413-1424. DOI: 10.1007/s00784-011-0642-8.

22. Spreafico R, Marchesi G, Turco G, et al. Evaluation of the in vitro effects of cervical marginal relocation using composite resins on the marginal quality of CAD/CAM crowns. J Adhes Dent 2016;18(4):355362. DOI: $10.3290 /$ j.jad.a36514.

23. Jassim ZM, Majeed MA. Comparative evaluation of the fracture strength of monolithic crowns fabricated from different all-ceramic CAD/CAM materials (an in vitro study). Biomed Pharmacol J 2018;11(3). DOI: $10.13005 / \mathrm{bpj} / 1538$.

24. Bankoğlu Güngör M, Karakoca Nemli S. Fracture resistance of CAD-CAM monolithic ceramic and veneered zirconia molar crowns after aging in a mastication simulator. J Prosthet Dent 2018;119(3):473-480. DOI: 10.1016/j.prosdent.2017.05.003.

25. Shillingburg $H$, Hobo $S$, Whitsett $L$, et al. Fundamentals of fixed prosthodontics. 4th ed. Chicago, IL: Quintessence Publishing Co; 2012. 119-130: 48-51, 20, 39-42, 51-52 p.

26. van Dijken JW, Kieri C, Carlén M. Longevity of extensive class II opensandwich restorations with a resin-modified glass-ionomer cement. JDent Res1999;78(7):1319-1325. DOI: 10.1177/00220345990780070601.

27. Vertolli TJ, Martinsen BD, Hanson CM, et al. Effect of deep margin elevation on CAD/CAM-fabricated ceramic inlays. Oper Dent 2020;45(6):608-617. DOI: 10.2341/18-315-L.

28. Marchesi G, Spreafico R, Frassetto A, et al. Cervical margin-relocation of CAD/CAM lithium disilicate ceramic crown using resin-composite. Dent Mater2014;30(Suppl. 1):e14. DOI: 10.1016/j.dental.2014.08.029.

29. Federlin M, Hiller KA, Schmalz G. Effect of selective enamel etching on clinical performance of CAD/CAM partial ceramic crowns luted with a self-adhesive resin cement. Clin Oral Investig 2014;18(8):1975-1984. DOI: 10.1007/s00784-013-1173-2. 